\title{
A PSICOMOTRICIDADE COMO FERRAMENTA DA APRENDIZAGEM
}

\author{
Lidiane Rodrigues Dorneles' Luciana Borba Benetti² \\ ${ }^{1}$ Pós-Graduada do Curso de Especialização em Educação: Interdisciplinaridade e Transversalidade, \\ Universidade Federal do Pampa. lidianedornelles@yahoo.com.br \\ ${ }^{2}$ Professora Adjunta da Universidade Federal do Pampa, \\ Campus São Gabriel lucianabenetti@unipampa.edu.br
}

Resumo: A problemática abordada neste trabalho tem como espaço de análise a necessidade de desvendar a concepção de educação psicomotora expressa pelos professores da educação infantil e identificar, de que maneira estes profissionais trabalham o desenvolvimento motor de seus alunos. A palavra psicomotricidade vem do termo grego psyché, alma, e do verbo latino moto, mover frequentemente. A psicomotricidade teve impulso no começo do século XX, na França, com o surgimento de várias linhas de pensamento biomédico, psicopedagógico e psicanalítico. A modalidade de pesquisa aplicada neste trabalho é de caráter exploratório, tendo como metodologia o referencial teórico. A transversalidade e a interdisciplinaridade apresentam as interfaces possíveis e colaboram para a abrangência e consistência do conhecimento. Todavia, a intervenção da Psicomotricidade Relacional favorece esta socialização podendo ser usada como ferramenta de intervenção na educação (PARÂMETROS CURRICULARES NACIONAIS, 1998).

Palavras-chave: Psicomotricidade; Desenvolvimento Infantil; Aprendizagem; PCNs.

Abstract:The problem addressed in this work is the analysis of space need to unveil the design of psychomotor education expressed by teachers of early childhood education and to identify how these professionals work the motor development of your students. The word comes from the Greek word psychépsychomotricity, alma, and the Latin verb bike move frequently. The psychomotricity took momentum in the early 20th century, in France, with the emergence of several lines of thought, biomedical and psicopedagógico psychoanalytic. The type of applied research in this work is exploratory in nature, having as referential theory, the methodology the transversality, interdisciplinarity and present possible interfaces and collaborate to the comprehensiveness and consistency of knowledge. However, the intervention of Relational Psychomotricity favors this socialization can be used as a tool of intervention in education (NATIONAL CURRICULAR PARAMETERS, 1998).

Key-words:Psychomotricity; Child Development; Learning; PCNs.

\section{INTRODUÇÃO}

A palavra psicomotricidade vem do termo grego psyché, alma, e do verbo latino moto, mover frequentemente. A psicomotricidade teve impulso no começo do século XX, na França, com o surgimento de várias linhas de pensamento biomédico, psicopedagógico e psicanalítico (BARRETO, 2000). 
A psicomotricidade nas aulas de Educação Física pode auxiliar na aprendizagem escolar, contribuindo para um fenômeno cultural que consiste de ações psicomotoras exercidas sobre o ser humano de maneira a favorecer comportamentos e transformações (BARRETO, 2000).

O primeiro a criar a noção de psicomotricidade da criança foi o neuropsiquiatraDupré (1909), a partir dos seus estudos sobre a síndrome da debilidade mental. Esses estudos têm sua predominância centrada numa concepção biomédica e numa visão cartesiana/newtoniana, vigente na época entre os cientistas (CAPRA, 1982).

Durante os séculos XVII E XVIII, conforme Santin (1994), a racionalidade dominou grande parte das culturas e fragmentou a dimensão humana nos seus limites, na qual ter uso da razão constituiu-se o único pressuposto para assegurar os plenos direitos de pertencer à humanidade.

A psicomotricidade adota como eixo norteador o aspecto funcional segundo o qual, no cumprimento de certas diretrizes corporais orientadas pelo professor, a criança adquire toda uma gama de habilidades motrizes capazes de prepará-la para as demandas da vida em atividades de envolvimento corporal (Selau 2010).

A problemática abordada tem como espaço de análise a necessidade de desvendar a concepção de educação psicomotora expressa pelos professores da educação infantil e identificar, de que maneira estes profissionais trabalham o desenvolvimento motor de seus alunos. Por isso, optou-se pela linha qualitativa de pesquisa.

Nesta perspectiva elaborou-se o seguinte problema de pesquisa: - Será que os professores dominam o conhecimento e aplicação da psicomotricidade como ferramenta da aprendizagem?

\section{DESENVOLVIMENTO TEÓRICO}

\section{A Psicomotricidade}

É a ciência que tem como objeto de estudo o homem através do seu corpo em movimento e em relação ao seu mundo interno e externo. Está relacionada ao processo de maturação, onde o corpo é a origem das aquisições cognitivas, afetivas e orgânicas. É sustentada por três conhecimentos básicos: o movimento, o intelecto e o afeto (ABP, 2007).

Psicomotricidade, portanto, é um termo empregado para uma concepção de movimento organizado e integrado, em função das experiências vividas pelo sujeito cuja ação é resultante de sua individualidade, sua linguagem e sua socialização (ABP, 2007).

Segundo Negrine (1998), a concepção de Wallon (1925)descrita na sua tese de doutorado "El niño turbulento", influenciou e contribuiu significativamente para os psicomotricistas que estudavam o desenvolvimento motor e mental da criança, tanto no aspecto intelectual quanto no motor e no afetivo. Dentre as inúmeras implicações psicopedagógicas que Wallon (1925) estudou, destaca-se o estudo da gestualidade. Para ele, o importante não é a materialidade do gesto, mas o contexto em que se manifesta. Refere que o gesto se inscreve na personalidade e serve para revelar sensibilidades desconhecidas, evidenciando, assim, que o movimento é um grande instrumento de manifestação do psiquismo.

O Francês Le Camus (1986) é um autor fundamentalmente teórico. Em suas obras analisa os autores teóricos e práticos e suas concepções. Sempre coloca em destaque que o centro de tudo está no pensamento de Wallon. Para Le Camus (1986), a psicomotricidade é, em sua 
evolução, dividida por três grandes impulsos: 0 primeiro nos anos 30 do século passado, quando se trabalhava a reeducação psicomotora (os testes serviam como instrumento de avaliação do perfil psicomotor, observados em um plano funcional). Sua aplicação ficava restrita a clínicas, executada por professores de Educação Física;O segundo grande impulso ocorreu por volta de 1960, quando se trabalhava a reeducação psicomotora e a terapia psicomotora. Nessa época, as concepções de Wallon entram em evidência;O terceiro, em torno de 1970, quando, além da reeducação e terapia psicomotora, ocorre a inclusão da educação psicomotora, pela qual há um deslocamento do corpo instrumental (regido por aspectos funcionais), para o corpo relacional, que busca uma abordagem mais global, contemplando o aspecto simbólico do movimento e lúdico do comportamento. Para Le Camus, essa mudança de enfoque da psicomotricidade se dá à luz dos trabalhos de Wallon.

Há também enfoques importantes que Le Camus (1986) relata em sua obra referente à crise entre os profissionais da área médica e os educadores físicos, por disputa de mercado, e à oficialização de mais duas profissões: a de reeducação e a da terapia psicomotora.

A concepção de Le Boulch surge a partir de sua tese de doutorado em 1960. Intitulada "Lesfacteurs de La valeurmotrice", na qual critica os métodos utilizados pela Educação Física e pela ginástica, por embasarem-se no dualismo cartesiano.

"Para tanto, propõe a "educação psicocinética" exposta na obra". "A educação pelo movimento: a psicocinética na idade escolar" (1983), que tem como proposta pedagógica a utilização do movimento de forma abrangente, como meio de educação global da criança. Tem como princípios norteadores o melhor ajuste do homem ao meio, desenvolvendo suas qualidades fundamentais, por meio dos jogos recreativos de livre expressão.

Le Boulch (1983), a partir dos estudos sobre a obra de Wallon (1925), refere que as carências de interação acarretem dificuldades no esquema corporal. Essas carências podem ser evidenciadas no jogo, pois este tem profunda repercussão emocional e grande carga expressiva, em que, através do simbólico, revelam-se as verdades e as frustrações, favorecendo os bloqueios afetivo-emocionais. Encontradas (seja no jogo, ou não) se dá pelo treinamento das valências psicomotoras. Apesar de Le Boulch (1983) ter como proposta pedagógica uma educação global, contradiz-se quando trata das dificuldades e as lacunas de aprendizagem por meio de exercícios específicos para o desenvolvimento de valências físicas, transparecendo, assim, um enfoque indefinido entre funcional e relacional que pende para o funcionalismo.

A concepção psicopedagógica da psicomotricidade é exposta pela primeira vez por Picq e Vayer (1969), com a obra "Educaciónpsicomotriz y retraso mental", na qual se utilizam da Educação Física com o objetivo de "melhorar o comportamento da criança", atuando no âmbito pedagógico e psicológico, opondo-se à dualidade psique-soma (mente e corpo) apoiando-se numa base psicobiológica que leva a uma concepção global e coerente de reeducação. Inicialmente, seus estudos convergiam para a inadaptação escolar. Acreditavam que a educação psicomotriz deveria atuar sobre as condutas motrizes de base (equilíbrio, coordenação etc.) e sobre as condutas sensório-motrizes (consciência, memória,organização espaço-temporal, ritmo, e outras).Já na obra "El diálogo corporal", Vayer (1972) toma apoio nos testes de Ozeretzki (1936) para avaliação do perfil psicomotor de crianças de dois a cinco anos. Posteriormente, com o trabalho "El niño frente al mundo" (1973), aproxima a educação intelectual da física e critica a sua separação. Oferece, porém, nova bateria de testes para avaliação do perfil psicomotor, para crianças de seis a onze anos, o que o configura como um psicomotricista funcional.

Para Negrine (1998), essas obras de Vayer trazem consigo influências do modelo biomédico e das famílias de exercícios da Educação Física. Apesar de ser uma proposta de atuação 
instrumental e mecânica do corpo da criança, contribui com os elementos relevantes para a psicomotricidade, pois, a partir de sua obra, começa-se a entendê-la como elemento da relação.

Lapierre e Aucouturier (1988) marcam o início da inovação da prática psicomotriz. De acordo com Negrine (1998), tanto as mudanças de enfoques do racionalismo ao naturalismo que a psicomotricidade sofreu nos últimos anos como as inovações teórico-práticas devem ser atribuídas ao trabalho desenvolvido por esses autores. Negrine (1998) entende que a trajetória percorrida por Lapierre e Aucouturier apresenta três períodos distintos: O período continuador - A aproximação de ideias que esses autores tiveram no período continuadoré marcada por algumas características que possuíam em comum: professores de Educação Física e psicorreeducadores. Negrine (1998) classifica esse período como continuador, pois seus trabalhos partem do princípio funcionalista da psicomotricidade, enraizada nas famílias de exercícios da Educação Física e nos exercícios-testes utilizados por Ozeretski (1936). É o que podemos constatar no livro de Lapierre e Aucouturier "Educação Vivenciada" (1988) "quando se situam claramente dentro de uma proposta racionalista ao tratar tanto da organização e estruturação espaço temporal quanto do esquema corporal" (NEGRINE, 1998,p.53).Apesar de, nesse tempo, a predominância de seus trabalhos partir de um ponto de vista racionalista, já podemos observar, em algumas obras, inquietações que são diferentes para o pensamento da época ( a importância do aspecto afetivo, uma atitude permissiva e não-diretiva) que foram fundamentais para que Lapierre e Aucouturier participassem para a realização de um projeto totalmente diferente; O período inovador - Negrine (1998) considera que a passagem da prática funcional para a relacional se deu com esses autores, Lapierre e Acouturier (sem esquecer que o enfoque funcional ocorre até os dias de hoje). $O$ período inovador é marcado pelo reconhecimento desses dois autores, em "A simbologia do movimento" (1988), sobre suas contradições e limitações; pela formação pessoal do adulto; e pelo abandono do modelo médico que consistia no diagnóstico mediante testes psicomotores, prescrição e tratamento.Dentro do marco relacional, o mais importante para Lapierre e Aucouturier é trabalhar com o que a criança tem de positivo e não se preocupar com o que ela não sabe fazer.

Para Negrine (1998, p.59):

A proposta inovadora da prática psicomotriz de Lapierree Aucouturirer é a introdução do jogo como componentepedagógico básico na sessão de prática psicomotriz, seja educativa, reeducativa ou terapêutica, com criança oucom adultos em formação pessoal.

O jogo, nesse sentido, em momentos dirigidos ou livres, refere-se ao brincar, fundamentalmente no sentido de valorizá-lo, ajudando a criança ou o adulto a lidar melhor com seus conflitos. Essa abordagem foi radical para época, final da década 70 do século passado, pois o modelo biomédico era o componente dominador no momento. Deu-se importância ao aspecto psicanalítico das atividades espontâneas, o que foi outro aspecto inovador; Período da ruptura Operíodo da ruptura se caracteriza pelo afastamento entre Lapierre e Aucouturier, causado por uma busca que cada um vai fazer sobre novos estudos. Suas diferenças teóricas fundamentais se caracterizam pela forma de intervenção com as crianças, em que: Aucouturier defende a tese de uma sessão que potencie o jogo sensório-motor e também que o adulto não deve se implicar corporalmente nos jogos simbólicos da criança; Lapierre, por sua vez,passa a desenvolver o jogo simbólico, implicando-se corporalmente no jogo da criança, quando necessário. 


\section{Concepções de Negrine para a Psicomotricidade Relacional no Brasil}

O autor brasileiro Airton Negrine, professor de Educação Física, estudou amplamente a questão funcionalista da Psicomotricidade, até que, em seus estudos para doutoramento, na Universidade de Barcelona, em 1993, com a tese "Juego y psicomotricidade" contribuiu para o desenvolvimento da Psicomotricidade Relacional no Brasil. Historicamente, aproxima a psicomotricidade da Educação Física. Sua atuação é teórico-prática, ou seja, ao mesmo tempo em que atua com crianças consideradas normais e crianças com necessidades educacionais especiais em sessões de Psicomotricidade Relacional, produz material teórico sobre seu trabalho. A Psicomotricidade Relacional possui uma abordagem centrada em aspectos da aprendizagem e desenvolvimento infantil, a partir da perspectiva lúdica, que não é racionalizado nem competitivo. Aproxima o seu pensamento ao de Vygotsky, considerando que a criança se desenvolve quando aprende, atribuindo grande importância ao jogo (simbolismo) e à implicação corporal do adulto. Negrine prediz que, durante o brincar, a criança joga de muitas coisas em determinado espaço de tempo, indo também ao exercício, para voltar ao jogo. Cita que o ser humano não perde o hábito de imaginar ou desfrutar que a atividade lúdica proporciona, pois o imaginário segue pela sua vida, tendo a pessoa adulta outras maneiras de manifestar sua necessidade lúdica, diferentemente das crianças.Consideraessenciais três pilares para a formação de psicomotricistasrelacionais: a formação teórica (que são os estudos teóricos do psicomotricista sobre a prática), a pedagógica (vivenciados psicomotricistas em formação com crianças, conjuntamente com professores formados) e a pessoal (via de formação do psicomotricistas por meio de dinâmicas de autoconhecimento, que dão suporte para a atuação corporal com as crianças).

Algumas de suas publicações na área: "Aprendizagem e desenvolvimento infantil: simbolismo e jogo" (1994); “Aprendizagem e desenvolvimento infantil: perspectivas psicopedagógicas" (1994); "Aprendizagem e desenvolvimento infantil: psicomotricidade: alternativas pedagógicas" (1998); "O corpo na Educação Infantil" (2002); "Terapias corporais" (1998).

Desde 1994 trabalha na formação de professores e também na formação de psicomotricistas com ênfase na Psicomotricidade Relacional, além da prática pedagógica que desenvolve com crianças nos cursos de pós-graduação. Seus mais recentes estudos dizem respeito à Psicomotricidade Relacional como alternativa pedagógica no trabalho com crianças ditas com necessidades educacionais especiais, como se observa no livro "Autismo infantil e terapia psicomotriz" (2004).

Definir uma abordagem pedagógica que se utiliza da atividade corporal lúdica (que não é racionalizada nem competitiva) para as crianças significa reconhecer o lúdico como característica fundamental do ser humano, focalizando, dessa maneira, o brincar como a principal atividade infantil (FALKENBACH, 2002).

O homem por si só é um ser social. As relações da criança em um grupo são muito importantes não só para a aprendizagem social, mas fundamental para a tomada de consciência de sua personalidade, assim como, para a valorização do próximo. Aprendendo a se colocar no lugar do outro e exercer a (tão utópica) inclusão. A obra de Saint-Exupéry - O Pequeno Príncipe nos mostra uma profunda mudança de valores, que ensina como nos equivocamos na avaliação das coisas e das pessoas que nos rodeiam: "Os homens compram tudo pronto nas lojas... Mas como não há loja de amigos, os homens não têm amigos". ( IESDE, 2007 ) 
Existe a referência dos Parâmetros Curriculares Nacionais do terceiro e quarto ciclo, para que sejam propostas atividades em grupo, proporcionados momentos para discussão e elaborações de trabalhos coletivos. Promovem o favorecimento das potencialidades como indicações de trabalho nas escolas (PARÂMETROS CURRICULARES NACIONAIS, 1998).

Todavia, a intervenção da Psicomotricidade Relacional favoreceesta socialização e a relação entre os alunos, por meio principalmente da aproximação corporal, estabelecida pela disponibilidade do adulto no setting, que facilita o contato entre as próprias crianças, como também, com próprio adulto. Podendo ser usada como ferramenta de intervenção na educação. Dentre as inúmeras finalidades da educação é imprescindível que os alunos aprendam a conviver em grupos, respeitem-se e estabeleçam boas relações de cooperação e produtividade. Nessa perspectiva, os Parâmetros Curriculares Nacionais (1997, p. 63) acordam que "são fundamentais as situações em que possam aprender a dialogar, a ouvir o outro e ajudá-lo, a pedir ajuda, aproveitar críticas, explicar um ponto de vista, coordenar ações para obter sucesso em uma tarefa conjunta", afirmando a importância da aprendizagem desses procedimentos para construção de uma identidade pessoal e coletiva. O criador da Psicomotricidade Relacional, André Lapierre, acredita "que o corpo não é essencialmente cognição, mas também o lugar de toda sensibilidade, afetividade, emoção da relação consigo e com o outro." Batista e Lapierre (2004).

Sendo assim, as relações inter e intrapessoais convergem para a construção do sujeito enquanto pessoa, e sujeito inserido na coletividade como afirma os PCN's.

A função do psicomotricista relacional no setting envolve "a capacidade de decodificar, intervir e responder de forma a proporcionar possibilidades de desenvolvimento e evolução em direção à autonomia e socialização." (Ibid., p. 100) A partir do reconhecimento do desenvolvimento individual e do processo de socialização, a escola irá potencializar as capacidades dos alunos, [...] de modo a auxiliá-los a desenvolver, no máximo de sua possibilidade, as capacidades de ordem cognitiva, afetiva, física, ética, estética e as de relação interpessoal e de inserção social, ao longo do ensino fundamental (1998). Lapierre e Aucouturier comentam que: A evolução da criança depende de sua inserção no grupo, de sua aceitação ou de sua rejeição, das possibilidades de comunicação que ela consegue estabelecer, mas também da estrutura, mais ou menos patogênica ou que proporcione equilíbrio, do grupo em que convive e das individualidades que o compõem. (2004, p. 21) Através da Psicomotricidade Relacional, por meio do jogo espontâneo, é possível identificar as dificuldades e as facilidades de cada criança a qual se mostra na sua inteireza na relação que estabelece com os outros, e assim percebê-la e valorizá-la como única.

Em 1762, Rousseau descreveu a infância e o desenvolvimento em seus estágios, do nascimento à puberdade, no romance Emílio. Onde "cogita, pela primeira vez, da necessidade de estudar a criança antes de querer educá-la". São suas palavras: "Começai por estudar vossos alunos, pois é bem certo que não os conheceis". Através da Psicologia do Desenvolvimento se contempla as reações intelectuais, sociais e emocionais em diferentes idades e se procura descobrir como elas mudam de acordo com a idade. Se como educadores, pensarmos no desenvolvimento da criança como um ser biopsicossocial, buscando atender aos aspectos físicos, afetivos, sociais e cognitivos, evidentemente que se faz necessária desde cedo à utilização ampla do movimento. $O$ movimento consciente pode ser realizado através da prática de atividades psicomotoras, como forma de auxiliar a criança na comunicação com o mundo através da ação, por meio do movimento e dos gestos, favorecendo o desenvolvimento integral e as aprendizagens. As primeiras evidências de um desenvolvimento normalmental são as manifestações motoras. 


\section{Psicomotricidade Vs. Aprendizagem}

"A educação psicomotora deve ser considerada como uma educação de base na escola primária. Ela condiciona os aprendizados pré-escolares e escolares; leva a criança a tomar consciência de seu corpo, da lateralidade, a situar-se no espaço, a dominar o tempo, a adquirir habilmente a coordenação de seus gestos e movimentos. A educação psicomotora deve ser praticada desde a mais tenra idade; conduzida com perseverança, permite prevenir inadaptações, difíceis de corrigir quando já estruturadas...". Baseado na obra L'éducation par Le mouvement 1966, um decreto ministerial em 1969 introduziu a educação psicomotora como prática semanal de seis horas na escola primária.

Um projeto de lei alterou a Lei n.o 9.394, de 20 de dezembro de 1996, estabelecendo as diretrizes e bases da educação nacional (LDB), incluindo o Art. 62-A, que afirma: "Os conteúdos curriculares da disciplina Educação Física no ensino infantil, fundamental e médio serão ministrados exclusivamente por Professores de Educação Física, licenciados em nível superior". No mesmo parecer é revelado a preocupação com a Educação Física Escolar. "Há estudos que revelam que a disciplina, sobretudo na esfera da Educação Pública, é oferecida de forma muito precária. No entanto, está comprovado que a Educação Física influencia positivamente o desenvolvimento da psicomotricidade, da sociabilidade e até do caráter do jovem".

\section{PCN Vs. Psicomotricidade}

Os Parâmetros Curriculares Nacionais foram criados com o intuito de contribuir com o processo educativo respeitando a diversidade comumente em nosso país e as necessidades de referências comuns atodas as regiões brasileiras. Tendo em vista, criar condições para construção do conhecimento em prol dos envolvidos neste processo.

Constituem objetivos fundamentais da República: construir uma sociedade livre, justa e solidária; garantir o desenvolvimento nacional; erradicar a pobreza e a marginalização e reduzir as desigualdades sociais e regionais; promover o bem de todos, sem preconceitos de origem, raça, sexo, cor, idade e quaisquer outras formas de discriminação (artigo 3 da Constituição Federal).

O fundamento da sociedade democrática é a constituição e o reconhecimento de sujeitos de direito. Na área educacional, são fundamentos que permitem orientar, analisar, julgar, criticar as ações pessoais, coletivas e políticas na direção da democracia. Os Parâmetros Curriculares Nacionais, ao propor uma educação comprometida com a cidadania, elegeram tais princípios para orientar a educação escolar, sendo eles: Dignidade da pessoa humana - Implica em respeito aos direitos humanos, repúdio à discriminação de qualquer tipo, acesso a condições de vida digna, respeito mútuo nas relações interpessoais, públicas e privadas; Igualdade de direitos - Refere-se à necessidade de garantir a todos a mesma dignidade e possibilidade de exercício de cidadania; Corresponsabilidade pela vida social - Implica em partilhar com os poderes públicos e diferentes grupos sociais, organizados ou não, a responsabilidade pelos destinos da vida coletiva.

Os Temas Transversais - Ética, Meio Ambiente, Pluralidade Cultural, Saúde, Orientação Sexual, Trabalho e Consumo - indica uma proposta metodológica para inclusão no currículo escolar. Abarca as relações e ações pessoais e em grupos, atribuídas as suas críticas. Contudo, permite analisar, confrontar e discutir o sentido ético da convivência humana na vida social em suas dimensões. 
Os Parâmetros Curriculares Nacionais estimulam a visão interdisciplinar do conhecimento.Como apresenta o gráfico abaixo:

\title{
Tranversalidade e Interdisciplinaridade
}

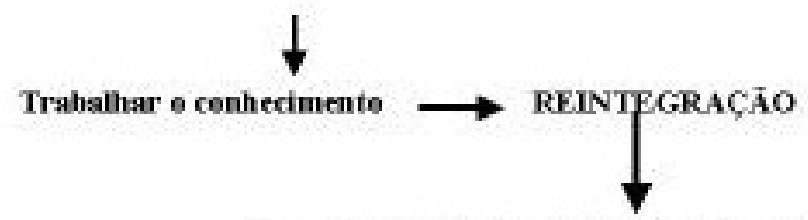

Visàe mais ampla e adequada da realidade

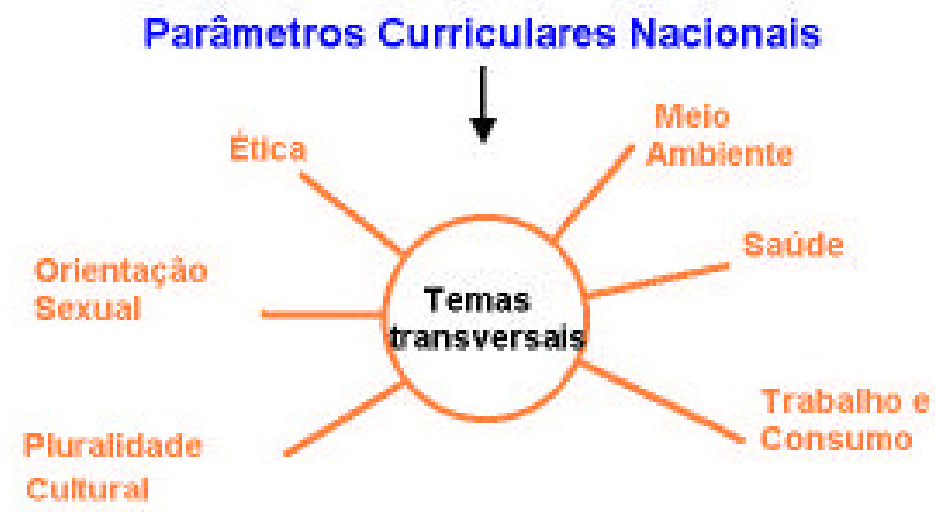

A disciplina delimita o objeto de estudo. A transversalidade e a interdisciplinaridadeo ampliam, apresentam as interfaces possíveis e colaboram para a abrangência e consistência do conhecimento.

De acordo com os PCNs (1997):

\begin{abstract}
A interdisciplinaridade refere-se a uma abordagem epistemológica dos objetos de conhecimento enquanto a transversalidade diz respeito principalmente à dimensão da didática. [...] A primeira questiona a visão compartimentada da realidade e refere-se, portanto, a uma relação entre disciplinas. Os temas transversais, portanto, dão sentido social a procedimentos e conceitos próprios das áreas convencionais, superando assim o aprender apenas pela necessidade escolar. Há afinidades maiores entre determinadas áreas e determinados temas. Não considerar essas especificidades seria cair num formalismo mecânico.
\end{abstract}

\section{Relato e solução quanto ao benefício das intervenções motoras}

Valeski et al. (2004) relataram um estudo de caso com um menino de 11 anos de idade com diagnóstico de TDAH que foi submetido a 8 sessões de intervenção fisioterapêutica com abordagem ludo terapêutica, duas vezes semanais, com duração de 40 minutos cada sessão. Foi trabalhado equilíbrio, coordenação motora, manipulação de objetos, marcha, postura, consciência 
do corpo e do espaço. Por meio da observação dos pesquisadores e relatos da mãe do paciente, a atuação mostrou-se eficiente na coordenação motora e na concentração da criança.

Outro programa de intervenção foi relatado por Majorek, Tuchekmann e Heusser (2004). Os autores estudaram cinco casos de crianças com TDAH e dificuldade de aprendizagem que participaram de uma terapia do movimento envolvendo elementos cognitivos, emocionais e volitivos, enfocando a linguagem e a atividade musical em relação ao movimento. A terapia consistiu de sessões de 30 minutos, realizadas uma vez semanal, sendo que o número de sessões por criança foi entre 7 e 25, dependendo do tempo disponível de cada aluno. Foram avaliados o equilíbrio, o ritmo e a coordenação óculo manual e óculo pedal por meio da Escala de LincolnOseretzky (LOS FK18). Os resultados mostraram melhora nas áreas avaliadas e nos problemas de comportamento social. A hiperatividade também diminuiu após a terapia, sugerindo que esta atividade pode ser eficaz em crianças com TDAH. Entretanto, os autores lembram que em virtude da amostra reduzida, apenas conclusões limitadas podem ser extraídas deste estudo.

\section{CONSIDERAÇÕES FINAIS}

A interpretação educacional é um caminho epistemológico onde comprova que a necessidade de se repensar os objetivos e métodos educacionais tornam-se profunda, com aparente inevitabilidade. Evidentemente que uma análise deve ser valorizada antes de ser cultivada em qualquer intervenção completa. A psicomotricidade tem-se mostrado aliada, criando oportunidades de multiplicar sua ação em conjunto com outras ciências e teorias de maneira funcional para a melhoria do ensino, da saúde e da qualidade de vida. Encontram-se nestes e outros vários autores, as adaptações a novos desafios que nos dão visões complementares e bases profissionais. Seja por meio da Ciência, Biologia, Filosofia, Psicologia, da Educação Física, podemos dizer que há um consenso quanto ao fato do processo de aprendizagem (ou construção dos saberes) depender das virtudes de sentimento, sensibilidade, criatividade, da imaginação e da afetividade enquanto busca do prazer (satisfação/realização) pessoal. Onde o precedente é o foco emoldurado em nossa civilização "Todos os homens por natureza desejam o saber" (epígrafe de Aristóteles).

Há alguns parâmetros que favorecem este trabalho diversificado: primeiro, o currículo, a interdisciplinaridade. Segundo: a mobilização das potencialidades em defesa da educação, dos cuidados infantis e desenvolvimento humano, mas antes de tudo, o educador terá de estar disposto a romper com o sistema convencional de ensino, para produzir saberes em diferentes níveis de aprendizagens. Diante disso, o papel do professor passa a ser ainda mais delicado do que em aulas tradicionais. Passando a ter a responsabilidade de ter total controle do seu próprio conhecimento tanto teórico quanto filosófico e psicológico. Cabe salientar que, há uma série de práticas imediatistas e mecânica no interior da escola por falta de entendimento por parte dos professores em relação à psicomotricidade, mesmo sabendo da importância, têm dificuldades em traduzi-la em prática concreta e fundamentada. Este desafio é ainda maior (a formação do professor).

O conceito de criatividade torna-se essencial para se decifrar esses processos de educação e para se aprimorar os mecanismos de ensino.

Para concretizarmos a escola centrada no aluno devemos resistir as enormes pressões atuais para a uniformidade. Formar seres humanos livres, pensantes, críticos, criativos, conscientes, participativos na construção de seus mundos, através da educação, é um momento essencial de todo acontecimento da humanização. Caso contrário, do que vale tantos saberes, 
tecnologias e tudo mais? Considerando a complexidade do ser humano, considera-se relevante conhecer estes caminhos para que o educador possa explorar estas/tais habilidades, não deixando de lado a conquista (de cada dia) da individualidade de cada criança no que diz respeito ao conhecimento do "EU" fazendo menção ao "Conhece-te a ti mesmo" de Sócrates, "Penso, logo existo" de Descartes. É nesse sentido que a psicomotricidade surge como ferramenta didática, através de ações pedagógicas (construtiva, significativa e global) voltadas para uma realidade de mutações, que facilitam a construção do conhecimento. Uma vez que se aprende melhor (na prática) solucionando problemas do que memorizando conceitos.

Daí a importância de se incentivar, nos círculos escolares, não só o exercício da Psicomotricidade, mas da interdisciplinaridade através da manifestação da criatividade nos seus mais diversos domínios e nas dimensões das múltiplas inteligências. Educação dos saberes, educação dos sentimentos, educação nas decisões e educação na ação. O efeito sóserá visível em nosso percurso existencial, pois a educação é um processo permanente de construção de identidade, uma inacabável construção de si mesmocom os outros.

Podemos dizer que o ser humano, em sua organização orgânica e psíquica, desde sua concepção até sua desintegração final, é resultado do seu desenvolvimento psicomotor.Em suma, psicomotricidade é a vivência do corpo, assim como, o movimento é sempre uma expressão de uma existência.Esta ciência da saúde e da educação existe nos menores e mais simplórios gestos e em todas as atividades que desenvolve a motricidade humana, visando ao conhecimento e ao domínio do seu próprio corpo. O ser humano está sempre em movimento, se deslocando entre ações incertas, aleatórias, em função de suas curiosidades, para tornar seus interesses mais claros aos seus olhos. A escola pode aproveitar esse movimento e incitar estímulos para um bom desenvolvimento ou, então, pode reprimi-lo de tal maneira que desencoraje a criança nas oportunidades de descobrir o mundo, que nada mais é que sua pesquisa com o meio. Tanto a falta de estímulos como um desnível na estimulação, com o consequente amadurecimento numa das áreas em detrimento das outras, pode dar origem a desajustes, disfunções e distúrbios psicomotores que irão afetar o processo de integração do indivíduo na sociedade. Por isso, quanto mais cedo os estímulos vierem, mais chances a criança terá de se tornar um adulto potencialmente bem sucedido.

Quando houver a conscienciosidade, por parte dos envolvidos, de que a educação pelo movimento é o "xeque- mate" e que os estímulos, desde o início de nossas vidas, são as estratégias para se (vencer) elucidar o jogo pedagógico. Aí então, o educador passará a ser um provocador, aquele que possibilitará os conflitos cognitivos e que criará estratégias para que estes conflitos transformem-se em conhecimento, ou seja, inteligência. Permitindo à criança sanar mais facilmente os problemas, não somente de sua escolaridade, mas preparando-a para a sua existência, essa atividade não ficará mais relegada ao segundo plano, sobretudo porque o professor constatará que esse instrumento de mediação é um meio insubstituível para afirmar o ser biopsicossocial.

Finalmente podemos colocar algumas ideias e desafios, pois no livre exercício da democracia é direito do ser humano expressar suas ideias e condições de como deve ser o procedimento: Que o ser humano seja estimulado/educado em todas as dimensões e potencialidades, numa educação dialógica, libertadora, redentora (ter consciência de si mesmo e do mundo que o circunda, conhecendo-se a si mesmo, suas capacidades e seus limites, ter base para leitura da sua história e do mundo); (esse conhecimento poderá viabilizar o trabalho dos temas transversais), idealizadora de uma qualidade de vida digna e cidadã, aproximando os homens um dos outros, sobre tudo a viver em amor. Isso comprova que educar é muito mais que 
transmitir conhecimentos. Essas ideias contemplam um processo contínuo. Do ponto de vista que, a escola pode ser vista e entendida como um espaço de mudanças e formação de identidade se contrapondo ao ambiente de sujeição pré- estabelecido pela escola e pela sociedade.

Levando em conta todas as propostas apresentadasé necessário que professores, instituições de Educação, Famílias (principal motivador) e alunos, todos aqueles que fazem parte deste processo estejam abertos a essas mudanças. Onde a educação deve ser pensada como um trabalho interdisciplinar de múltiplas integradase mútuas interações na construção solidária de saberes, um lugar de trocas de afetos e de sentidos do aprendizado. Pois a educação é um bem em si mesmo e uma via de mão-dupla. Através da qual construímos e compartilhamos um legado (música, arte, teorias, sem esquecer das amizades, do amor e da eterna poesia) é o que levamos e o que também deixamos. E nessa história infinda de trocas de saberes, de valores, de sentidos e de sensibilidades cada um de nós tem uma missão. Logo, necessitamos zelar pela educação;temos uma grande responsabilidade em nossas mãos (não nos esqueçamos do que é perene). Qual poderá ser o nosso papel, como educadores na formação desses pequeninos cidadãos, de abrir as portas da inventividade ampla permitindo ousar, exprimir seus sentimentos e a própria forma de ver a vida em sua essência, reconhecendo o outro e descobrindo a si mesmo? Essa questão (que traz à luz a ciência do pensar) é um dos motivos do título com que abrimos este artigo e vamos deixá-la aqui, visando que se constitua em questão para cada um dos leitores quem sabe ousar filosofar.

P.S.: Psicomotricidade, ciência de corpo e alma do ser... Sua essência é uma arte, que se integra a outras artes, que da à luz a vida, conduz ao equilíbrio e a perene liberdade; Essência que busca pela excelência entre os extremos: nascimento e desintegração final. (Lidiane Dorneles, 2012).

\section{REFERÊNCIAS BIBLIOGRÁFICAS}

ALVES PROF. RICARDO C. S.ABP, 2007. Disponível em:<http://www.psicomotricialves.com/Psicomotricidadel.pdf.> Acesso em: 12 de janeiro de 2012. CONSELHO FEDERAL DE EDUCAÇÃO FÍSICA. Disponível em:<http://www.confef.org.br/extra/revistaef/show.asp?id=3852> Acesso em: 12 de janeiro de 2012. BARROS, Célia Silva Guimarães. Pontos de Psicologia Desenvolvimento. Ed. Ática, São Paulo, 1991. BARRETO, Sidirley de Jesús. Psicomotricidade, educação e reeducação. $2^{a}$ ed. Blumenau: Livraria Acadêmica, 2000.

BRASIL. Parâmetros Curriculares Nacionais: Introdução aos Parâmetros Curriculares nacionais/Ministério de Educação. Secretaria da Educação Fundamental. -3. ed. Vol. 01 - Brasília: A Secretaria, 2001.

BRASIL. Parâmetros Curriculares Nacionais. MINISTÉRIO DA EDUCAÇÃO E DO DESPORTO, Brasília: MEC/SEF, v. 9, 1998.

BRASIL. Parâmetros Curriculares Nacionais: Educação Física. Ministério da Educação e do Desporto. Secretaria de Educação Fundamental. Brasília: MEC / SEF, 1997.

CAPRA, F. O ponto de mutação: a ciência, a sociedade e a cultura emergente. São Paulo: Cultrix, 1982. DUPRÉ, E; MERKLEN, P. La débilitémotricedanssesrapportsavecladébilité mental. Nantes: Rapport de 19 émeCongrésdesAliéstes et NeurologistesFrançais, 1909.

FALKENBACH, A. A educação física na escola: Uma experiência como professor. Lajeado: Editora da Unitaves, 2002. 
FURINI, Anselmo Barce (Org.) ; SELAU, Bento (Org.) . Psicomotricidade relacional e inclusão na escola. 1. ed. Lajeado: Univates, 2010. v. 500. 164 p.

GARDNER, H.Estruturas da mente. Porto Alegre: Artes M., 1994.

WALLON, H. L'enfant turbulent. Paris: Press Universitaires de France, 1925.

LAPIERRE \& AUCOUTURIER. A Simbologia do Movimento: Psicomotricidade e Educação. Porto Alegre:

Artes Médicas, 1986.

LE CAMUS, J. O corpo em discussão: da reeducação psicomotora às terapias de mediação corporal. Porto Alegre: Artes Médicas, 1986.

LE BOUCH, J. (1960). Lesfacteurs de La valeurmotrice: analyseexpérimentale de certains de cesfacteurs : interprétation d'um point de vuephysiologique. Thèse ( Doctorat) Universidad de Rennes, Rennes, 1960.

. J. A educação pelo movimento - A psicocinética na idade escolar. Porto

Alegre: Artes Médicas, 1983.

. O desenvolvimento psicomotor do nascimento até 6 anos. Porto Alegre, ArtesMédicas, 1984.

MAJOREK, M.; TUCHELMANN, T.; HEUSSER, P. Therapeutic Eurythamy - movement therapy for children with attention déficit hyperactivity disorder (ADHD): a pilot study. ComplementaryTherapies in Nursing\&Midwifery, v. 10, p. 46-53, 2004.

NEGRINE, A. S.; MACHADO, M. L. S. Autismo infantil e terapia psicomotriz: estudos de casos. Caxias do Sul: Ed. da Universidade de Caxias do Sul, 2004.

A. Juego y psicomotricidade. 1993. 477 p.tesis (DoctoradoenFilosofía y Ciências de La Educación) -

Depto. De Didáctica y Organización Escolar, Facultad de Pedagogia de La Universidad de Barcelona, Barcelona, 1993.

A. Aprendizagem e desenvolvimento infantil 1: simbolismo e jogo. Porto Alegre: Edita, 1994.

1994. Aprendizagem e desenvolvimento infantil 2: perspectivas psicopedagógicas. Porto Alegre: Edita,

. Aprendizagem e desenvolvimento infantil 3: psicomotricidade: alternativas pedagógicas. 2. Ed. Porto Alegre: Edita, 1998.

. Terapias corporais: a formação pessoal do adulto. Porto Alegre: Edita, 1998.

O corpo na educação infantil. Caxias do Sul: Editora da Universidade de Caxias do Sul, 2002.

OZERETZKI, N. Echellemétriquedudéveloppement de lamotricité chez l'efant et l'adolescent. París: Higiene Mentale, 1936, p.53-75.

PICQ, L.;VAYER, P. EducaciónPsicomotriz y retraso mental: aplicación a los

diversos tipos de inadaptación. Barcelona, España: Editorial Científico-Médica, 1969.

SANTIN, Silvio. Educação Física: da alegria do lúdico à opressão do rendimento. Porto

Alegre, RS: ESEF - UFRGS, 1994.

SILVA, Daniel Vieira da ; HAETINGER, Max Gunther . Ludicidade e Psicomotricidade. 1. ed. Curitiba: IESDE Brasil Itda, 2007.

VALESKI, A.; COELHO, B.L.P.; RODRIGUES, M.C. Transtorno de déficit de atenção/hiperatividade: tratamento fisioterapêutico com abordagem ludoterapêutica. Fisioterapia Brasil, v. 5, n.1, p. 66-72, jan./fev. 2004.

VAYER, P.. El dialogo corporal. Barcelona: Ed. Científica Médica, 1972.

. El niño frente al mundo. Barcelona: Cientifico-Médica, 1973.

VYGOTSKI, L. S. A formação da mente. 6. Ed. Porto Alegre: Martins Fontes, 1998. 